\title{
Unintended Pregnancies, Restrictive Abortion Laws, and Abortion Demand
}

\author{
Marshall H. Medoff \\ Department of Economics, California State University, Long Beach, CA 90840, USA \\ Correspondence should be addressed to Marshall H. Medoff, marshall.medoff@csulb.edu
}

Received 25 September 2012; Accepted 21 November 2012

Academic Editors: P. D. Murphy, A. Rodriguez-Alvarez, and M. Tsionas

Copyright () 2012 Marshall H. Medoff. This is an open access article distributed under the Creative Commons Attribution License, which permits unrestricted use, distribution, and reproduction in any medium, provided the original work is properly cited.

This study examines the effect restrictive state abortion laws have on the pregnancy resolution decisions of women with unintended pregnancies. The empirical results find that the abortion ratio and the abortion rate of unintended pregnancies are more sensitive to increases in the abortion price than previous estimates that analyzed total pregnancies (unintended and intended). A Medicaid funding restriction has very little effect on a state's abortion rate of unintended pregnancies, but causes a larger decrease in the number of abortions of unintended pregnancies than previous estimates. A parental involvement law is associated with a significant reduction in a state's abortion ratio and the abortion rate of unintended pregnancies, which suggests that the law may have a behavioral modification effect. Neither a mandatory counseling law nor a two-visit law has a significant effect on a state's abortion ratio and the abortion rate of unintended pregnancies.

\section{Introduction}

The U.S. Supreme Court's 1973 Roe v. Wade decision legalizing abortion recognized that states have the right to regulate the procedure. The Court ruled that, during the first trimester of pregnancy, states could not enact any laws that restricted a woman's access to an abortion. During the second trimester, states could enact laws regulating abortion access, but only if the law had a compelling interest in protecting a pregnant woman's maternal health. During the third trimester, when the fetus is viable, states could enact laws restricting or even prohibiting abortions provided there was a medical exception to protect the life or health of the pregnant woman.

In 1992, the Supreme Court in Planned Parenthood of Southeastern Pennsylvania v. Casey rejected Roe's rigid trimester pregnancy framework of state abortion regulation and replaced it with the "undue burden" standard. The Court declared that states could impose restrictions on a woman's access to an abortion provided that the state law or regulation did not have "... the purpose or effect of placing a substantial obstacle in the path of a woman seeking an abortion of a nonviable fetus."
Restrictive state abortion laws may influence the likelihood of women terminating an unintended pregnancy in two ways. First, restrictive abortion laws increase the financial costs (e.g., out-of-pocket expenses on travel and accommodations, the price of the abortion procedure, lost work time, and childcare expenses) and the emotional costs (e.g., guilt, psychological trauma, remorse, regret, and humiliation) incurred by women seeking an abortion. Second, restrictive abortion laws may decrease the availability of abortion services by reducing the number of abortion providers resulting in an increase in both women's search costs in locating an abortion provider and the time costs associated with obtaining an abortion. The more restrictive the abortion law, the more costly the abortion. If abortions become more costly, women will have fewer of them.

Researchers from a number of academic disciplines have examined the impact various restrictive state abortion laws have on the demand for abortion. Since the demand for abortion is a function of unintended pregnancy, the ideal variable to study is the incidence of unintended pregnancies that result in an abortion. Either of two different dependent variables can be analyzed: (1) the abortion ratio (the number of abortions of unintended pregnancies per 
1000 unintended pregnancies) or (2) the abortion rate (the number of abortions of unintended pregnancies per 1000 women of childbearing ages 15-44 years). Conceptually, these are two different variables. The abortion ratio measures the likelihood that an unintended pregnancy will result in an abortion (i.e., the abortion ratio considers only those women who have an unintended pregnancy). The abortion rate measures the likelihood that women of childbearing age have an unintended pregnancy and that unintended pregnancy is terminated (i.e., the abortion rate considers all women of childbearing age: those who are not sexually active and those who are sexually active and practice safe or unsafe sex).

No studies have examined the effect restrictive abortion laws have on women's unintended pregnancy resolution decisions. The reason is that data on unintended pregnancies that result in an abortion are unavailable. That being the case, previous studies on the impact of restrictive state abortion laws have used the total number of pregnancies. The total number of pregnancies is the sum of unintended and intended pregnancies. As a consequence, previous estimates of the impact of restrictive abortion laws may have underestimated the actual impact on the incidence of abortion since the total number of pregnancies includes women with intended pregnancies who are virtually certain they want to have a child. Women with intended pregnancies are not affected by restrictive abortion laws, which should bias the impact of restrictive abortion laws toward zero.

However, the Center for Disease Control's Pregnancy Risk Assessment Monitoring System (PRAMS) conducted a state-specific survey of women's pregnancy intentions before, during, and after a birth in 2006. Using the PRAM's intention data plus similar state survey data, Finer and Kost [1] calculated state-level estimates of the proportion of births that were unintended and applied these proportions to the total number of births reported for each state for 2006 from the U.S. Vital Statistics Report. This data combined with the number of abortions obtained by residents of each state (and fetal losses) was used to estimate the number of unintended pregnancies for all 50 states in 2006. Finer and Kost's data makes it possible to estimate the impact of restrictive abortion laws on the incidence of abortions of unintended pregnancies.

The purpose of this paper is to use this 2006 data source to empirically estimate the impact of restrictive state abortion laws on the incidence of abortions of unintended pregnancies. The question of what effect restrictive abortion laws have on the incidence of unintended pregnancies that result in an abortion has significant public and social policy implications.

\section{Restrictive State Abortion Laws}

The Supreme Court has ruled there are four types of state laws that restrict a woman's access to an abortion that are constitutionally permitted.

Medicaid is a joint federal and state health insurance program that funds medical services for the poor. In 1980, the Supreme Court ruled that an amendment passed by
Congress in 1976 that prohibited the use of federal Medicaid funds to pay for abortions was constitutional. The decision of whether to fund Medicaid abortions was left to the sole discretion of each state. Many states enacted laws that prohibited the public funding of Medicaid abortions for lowincome women. State laws prohibiting Medicaid funding increase the out-of-pocket cost of abortion services for lowincome women.

Since the 1973 Roe v. Wade decision, the Supreme Court has held that while unmarried teen minors (less than eighteen years of age) have a constitutional right to obtain an abortion, a state could require that a parent be involved in a teen minor's abortion decision. Parental involvement laws require that a parent be notified or give permission before an abortion is performed on an unmarried teen minor. Parental involvement laws increase the emotional cost as well as the out-of-pocket money expense of a teen minor obtaining an abortion.

Mandatory counseling laws require that women receive state-mandated abortion-specific medical information about the procedure and then wait one hour to three days before obtaining an abortion. Although the content of the abortion information varies from state to state, it generally covers such topics as fetal development, gestational age of the fetus, purported link with breast cancer, mental health risks, infertility, and adoption options. Typically, the mandatory counseling does not have to be in person and is done by mail, fax, phone, or the Internet. The implicit intent of mandatory counseling laws is to increase the emotional costs to women and dissuade women from terminating an unintended pregnancy.

In 2006, five states had two-visit laws that require that women receive the mandatory counseling materials in person at least 24 hours before the abortion procedure. Twovisit laws necessitate that women seeking an abortion must make two separate trips to the abortion provider: one for the sole purpose of receiving the state-mandated medical information and then a second trip to obtain the abortion. Two-visit laws impose substantial travel expenses and time costs on women seeking an abortion.

\section{Theory}

The demand for abortion is assumed to be a function of the cost of an abortion and the number of unintended pregnancies which, in turn, is assumed to be a function of the cost of an abortion and the effectiveness of other contraceptive methods.

More specifically

$$
A=f(C, U P(C), Z),
$$

where $A$ is the number of abortions, $C$ is the cost of an abortion, $U P$ is the number of unintended pregnancies, and $Z$ is a vector of alternative contraceptive methods. The cost of an abortion $C$ may refer to either the direct cost (price of an abortion) or the indirect cost (a restrictive state abortion law).

It is assumed that abortions follow the fundamental law of demand (i.e., an increase in the cost of obtaining 
an abortion causes a reduction in the demand for abortion services: $\partial A / \partial C<0)$. Also, increases in the number of unintended pregnancies will increase the number of abortions $(\partial A / \partial U P>0)$ since some of the increase in the number of unintended pregnancies is unwanted and will be terminated.

An increase in the cost of an abortion $C$, due to the imposition of a restrictive abortion law, from (1) is given by

$$
\frac{d A}{d C}=\frac{\partial A}{\partial C}+\frac{\partial A}{\partial U P} \frac{\partial U P}{\partial C}
$$

If women incorporate the increase in abortion costs $C$, after an unintended pregnancy occurs, then $\partial U P / \partial C=0$ and the second term on the right-hand side of (2) is zero. The remaining first term $(\partial A / \partial C)$ on the right-hand side of (2) is the change in the abortion ratio: the reduction in the number of abortions of women with unintended pregnancies as a consequence of the enforcement of a restrictive abortion law (i.e., $\partial$ Abortion Ratio/ $\partial C<0$ ).

But women may incorporate the increase in the cost of an abortion in their decision making regarding their level of pregnancy avoidance. An increase in the cost of an abortion increases the cost of engaging in noncontracepted sexual activity relative to the cost of engaging in contracepted sexual activity and may induce fecund women away from the abortion option and towards alternative birth control methods that reduce the likelihood of an unintended pregnancy $(\partial U P / \partial C<0)$. It follows from $(2)$ that, if abortion costs alter the likelihood of an unintended pregnancy, an increase in the cost of an abortion $C$ will decrease the number of unintended pregnancies and, concomitantly, the number of abortions of unintended pregnancies.

Thus (2) yields two empirically verifiable hypotheses: (i) if the fundamental law of demand is valid, then an increase in the cost of an abortion, due to the imposition of a restrictive abortion law, will reduce the abortion ratio (i.e., the number of abortions of women with unintended pregnancies per 1000 unintended pregnancies), and (ii) if abortion costs alter women's pregnancy avoidance behavior, then the reduction in the number of abortions due to the increase in the cost of an abortion should be greater (of larger magnitude) on the abortion rate (number of abortions of unintended pregnancies per 1000 women of childbearing age) than on the abortion ratio.

\section{Literature Review}

One of the most frequently analyzed restrictive state abortion laws is Medicaid funding restrictions, which prohibit a state from using its public funds to pay for abortions for poor women. In general, the empirical results from most studies find that a Medicaid funding restriction lowers the abortion rate by 3 to 5 percent [2-6].

A considerable research has examined the impact of parental involvement laws, which require the notification or consent of an unmarried teen minor's parent before an abortion can be performed. Empirical estimates of the numerical impact of a parental involvement law range from no effect to a 6 percent reduction in the abortion rate of all women of childbearing age $[2,4,6,7]$.

Much less attention has been directed to the study of the impact of mandatory counseling laws which require that women receive state-mandated medical information about the abortion procedure. The few studies have found that mandatory counseling laws have no statistically significant impact on abortion demand [8-10]. This suggests that mandatory counseling laws represent a negligible increase in the effective total cost of obtaining an abortion to women (i.e., there is no requirement that women must read any material they receive).

All of the aforementioned studies use abortion data based on the total number of pregnancies of women of reproductive age. As noted previously, the total number of pregnancies includes both unintended and intended pregnancies, which may tend to underestimate the numerical impact of restrictive abortion laws on the incidence of abortions of unintended pregnancies.

\section{Data}

All the socioeconomic data used in this study are available in the US Census of Population [11]. The data on the religious denominations in each state are from the Association of Religion Data Archives [12]. Data on the status of state restrictive abortion laws were from the Guttmacher Institute [13]. Summary statistics for all the variables appear in Table 1.

\section{Empirical Model}

The economic theory of fertility control argues that the determinants of abortion demand are the opportunity cost of childrearing (labor market experience and education), revealed tastes for children and the direct (price of an abortion) and indirect (restrictive abortion laws) cost of obtaining an abortion [14-16]. During any given year some states enforced restrictive abortion laws and other states did not. Thus, one can think of the effects of restrictive abortion laws on abortion demand as a natural experiment with a treatment group (states with restrictive abortion laws) and a control group (states without restrictive abortion laws). A multivariate regression model is estimated in order to control for differences in the state population characteristics of women of childbearing ages 15-44 years. The functional form of the abortion demand model is given by the following equation:

$$
\begin{aligned}
& \text { Abortion Ratio }_{i} \text { or Rate } \\
& =b_{0}+b_{1} \text { Abortion Price }_{i} \\
& +b_{2} \text { Restrictive Abortion Laws } i \\
& +b_{3} X_{i} .
\end{aligned}
$$

6.1. Dependent Variable. The dependent variable is either the abortion ratio (the number of abortions of unintended pregnancies per 1000 unintended pregnancies) or the abortion 
TABLE 1: Summary statistics.

\begin{tabular}{lcc}
\hline Variable & Mean & $\begin{array}{c}\text { Standard } \\
\text { deviation }\end{array}$ \\
\hline Abortion rate of unintended pregnancies & 16.07 & 7.43 \\
Abortion ratio of unintended pregnancies & 304.00 & 108.77 \\
Abortion price & 446.20 & 103.08 \\
Labor force participation & 83.84 & 2.85 \\
Married & 64.53 & 4.13 \\
Education & 82.35 & 4.40 \\
Evangelical Christians & 15.40 & 13.68 \\
TANF & 336.46 & 135.92 \\
NARAL antiabortion attitudes & 25.50 & 14.43 \\
No Medicaid funding & .66 & .47 \\
Parental involvement law & .64 & .48 \\
Mandatory counseling law & .48 & .50 \\
Two-visit law & .10 & .30 \\
\hline
\end{tabular}

rate (the number of abortions of unintended pregnancies per 1000 women of childbearing ages $15-44$ years) in state $i=1,2, \ldots, 50$ during the year 2006 .

6.2. Abortion Costs. The direct cost of an abortion-Abortion Price - is the average cost of an abortion performed in a nonhospital facility during the first trimester of pregnancy in state $i$ in 2006. The indicator variable No Medicaid Funding equals one if state $i$ did not allow its public funds to be used to pay for Medicaid abortions for poor women in 2006. The variable Parental Involvement Law equals one if state $i$ required parental involvement prior to an unmarried teen minor having an abortion. The variable Mandatory Counseling Law equals one if state $i$ requires that an abortion provider give to women state-mandated abortion-specific medical information before the abortion procedure. The variable Two-Visit Law equals one if state $i$ requires that the medical information be provided in person and that the counseling take place at least 24 hours before the procedure thereby necessitating two separate trips to the provider. All of the restrictive abortion laws were enacted in states prior to 2006.

6.3. Opportunity Cost Factors. The variable $X$ is a vector of state-level controls for the socioeconomic characteristics of women of childbearing age: (i) labor force participation rate of women ages 16-44: women in the labor force have a greater opportunity cost of childbearing; (ii) married-the percentage of women ages 18-44 who are married: married women are more likely to use contraception as well as have planned pregnancies; (iii) College-the percentage of women ages $25-44$ who have a college degree: women with relatively greater human capital investment have a higher opportunity cost of childbearing and are better informed about the effectiveness of various contraceptive methods; (iv) TANF - the average temporary assistance to needy families payment received by an unmarried woman with one child in state $i$ in 2006: it has been argued that because welfare benefits are based on unwed marital status, the generosity of a state's public assistance may provide a financial incentive for unwed women to have unintended pregnancies and raise the child.

6.4. Revealed Tastes for Children. A woman's unintended pregnancy resolution decision may depend on the intensity of her commitment to her religion's moral opposition to abortion. The Catholic Church has a clear, unmistakable, and unequivocal position in opposition to abortion. However, there is considerable evidence that Catholic women do not uniformly support the Catholic Church's official position on abortion [17-19].

One religious group that requires strict adherence to its moral absolutes about the sanctity of life, premarital sexual activity, and the importance of a large family is Evangelical Christians. The increased presence of Evangelical Christians in a state may diminish the number of abortions. The variable Evangelical Christians is the percentage of a state's population that belongs to a religious denomination (other than Catholic) that teaches abortion is always unacceptable.

In addition, the philosophical beliefs of a state's residents regarding women's sexual activity, contraceptive practices, and abortion may influence both the restrictiveness of a state's abortion policies and the risky sexual behavior of women of childbearing age. Differences may exist in the attitudes among a state's residents that are specific to each state and may affect women's unintended pregnancy resolution decision. The antiabortion attitudes of a state are quantified by using NARAL Pro-Choice America's [20] rank of each state from 1 (least restrictive) to 50 (most restrictive) based on the number of policies a state has enacted that restrict women's access to reproductive healthcare in 2006.

\section{Empirical Results}

In the abortion demand equation (3) the abortion price cannot be treated as exogenous since, as noted by Levine [21], "... prices are determined by those who supply abortion services and those who demand them." The econometric solution to this problem is to find instruments for the abortion price, that are correlated with the abortion price, but do not directly affect the demand for abortion and then estimate the abortion demand equation using two-stage least squares [22]. Following Blank et al. [3], the instruments selected for the abortion price are (i) the number of nurses per 100,000 women of reproductive ages 15-44; (ii) the number of non-OB/GYN (obstetric/gynecologist) physicians per 100,000 women of reproductive ages; (iii) the number of hospitals in 2006. These three variables are related to the overall level of availability and accessibility of general medical services for women in a state, but should not be significantly affected by the demand for abortion within a state.

The two-stage least-squares estimates of the abortion demand equation are reported in Table 2, column 1, for the abortion ratio and column 2 for the abortion rate. In the interest of brevity, only the regression coefficients for the abortion cost variables are reported (the complete 
TABLE 2: Regression coefficients of abortion cost variables on abortion demand.

\begin{tabular}{lcc}
\hline \multirow{2}{*}{ Restrictive abortion law } & \multicolumn{2}{c}{ Dependent variable } \\
& Abortion ratio (1) & Abortion rate (2) \\
\hline Abortion price & $-1.595(2.23)^{* *}$ & $-.142(2.85)^{* * *}$ \\
No medicaid funding & $-121.591(1.91)^{*}$ & $-10.731(2.18)^{* *}$ \\
Parental involvement law & $-145.983(2.73)^{* * *}$ & $-10.179(2.44)^{* *}$ \\
Mandatory counseling law & $41.227(.92)$ & $1.187(.32)$ \\
Two-visit law & $-73.466(1.42)$ & $-3.378(.85)$ \\
\hline$R^{2}$ & .78 & .67 \\
\hline
\end{tabular}

Absolute value of $t$-statistics in parentheses; ${ }^{*} P<.10,{ }^{*} P<.05$, ${ }^{* * *} P<$ .01 . Abortion ratio is the number of abortions of unintended pregnancies per 1000 unintended pregnancies. Abortion rate is the number of abortions of unintended pregnancies per 1000 women of childbearing ages 15-44 years.

empirical results are available upon request). Each entry in Table 2 represents the estimated regression coefficient of the abortion cost variables (as well as the absolute value of the $t$-statistic in parentheses below the coefficient).

The empirical results reported in Table 2 indicate strong policy effects on the number of abortions of unintended pregnancies. The price of an abortion $(P<.05)$, no Medicaid funding $(P<.05)$, and a parental involvement law $(P<.05)$ all have a significantly negative impact on a state's abortion ratio and abortion rate of unintended pregnancies.

The estimated coefficient of the abortion price variable suggests that women with an unintended pregnancy are relatively sensitive to increases in the cost of an abortion. A fifty dollar increase in the price of an abortion reduces a state's abortion ratio by 79.75 abortions of unintended pregnancies (or equivalently a reduction in a state's abortion ratio of unintended pregnancies by roughly 8 percentage points) and a reduction in a state's abortion rate by 7.1 abortions of unintended pregnancies per 1000 women of reproductive age (or equivalently a reduction in a state's abortion rate of unintended pregnancies by .7 percentage points).

McCloskey and Ziliak [23] argue that it is more useful to describe the impact of a regression coefficient of an economic variable in terms of its numerical impact on the dependent variable (i.e., its elasticity of demand). A price elasticity of demand is a numerical measure of the responsiveness (change) of the dependent variable in the abortion demand equation-the number of abortions of unintended pregnancies - resulting from a $1 \%$ change in the price of an abortion. For a linear relationship [24, page 168], such as the abortion demand equation (3), the price elasticity of demand $\left(E_{p}\right)$ equals $E_{p}=b_{p}$. (mean of the abortion price/mean of the demand for abortion), where " $b_{p}$ " is the estimated regression coefficient of the abortion price variable that appears in Table 2, column 1 or column 2.

When the abortion ratio is the dependent variable, the price elasticity of demand is equal to -2.3 . When the abortion rate is the dependent variable, the price elasticity of demand equals -3.9 . Prior research, using the total number of pregnancies, found that the price elasticity of demand for abortions tended to be relatively unresponsive to increases in the price of an abortion ranging from .68 to $1.1[19,25,26]$. This suggests that women with unintended pregnancies are highly sensitive to increases in the price of an abortion. In other words, the pregnancy resolution decisions of women with unintended pregnancies are much more sensitive to increases in the price of an abortion than prior estimates that analyzed total pregnancies (unintended and intended).

In addition, the larger figure for the price elasticity of demand when the abortion rate is the dependent variable is consistent with the hypothesis that the cost of an abortion alters women's decisions regarding ex ante contraceptive usage that affects the likelihood of an unintended pregnancy $[21,27]$. The increase in the price of an abortion induces women to adopt alternative birth control methods (other than abortion) resulting in a decrease in both the number of unintended pregnancies and the subsequent number of abortions of unintended pregnancies and concomitantly a greater reduction in the abortion rate of unintended pregnancies than the abortion ratio of unintended pregnancies.

A medicaid funding restriction reduces a state's abortion rate by 10.7 abortions of unintended pregnancies per 1000 women of childbearing age (or equivalently a decrease in a state's abortion rate by 1 percentage point) and a state's abortion ratio by 121.5 abortions of unintended pregnancies per 1000 unintended pregnancies (or equivalently a decrease in a state's abortion ratio by 12.1 percentage points) as compared to states without a Medicaid funding restriction of abortions. These figures indicate that a Medicaid funding restriction has very little effect on women's risky (unprotected) sexual activity but, conditional upon an unintended pregnancy, a Medicaid funding restriction causes a relatively large reduction in the number of abortions of unintended pregnancies of the low-income population than the previous estimates of 3 to 6 percent [3-5].

A parental involvement law $(P<.05)$ reduces a state's abortion rate by 10.1 abortions of unintended pregnancies per 1000 women of reproductive age (or equivalently a decrease in a state's abortion rate by 1 percentage point) and a reduction in a state's abortion ratio by 145.9 abortions of unintended pregnancies per 1000 unintended pregnancies (or equivalently a reduction in a state's abortion ratio by roughly 15 percentage points). This large reduction in a state's abortion ratio may seem paradoxical since, theoretically, parental involvement laws only impact unmarried teen minors who represent only 6 to 8 percent of all abortions.

However, this result is entirely consistent with the interpretation that the enforcement of a parental involvement law has temporal effects that induce a permanent change in the unprotected sexual behavior of teen minors which is perpetuated as they age. This spillover effect is supported by Joyce and Kaestner's [28] finding that in Mississippi and South Carolina, after the imposition of a parental involvement law, the abortion rate of nonminors who were not affected by the law fell and Tomal's [29] finding that the enforcement of a parental involvement law decreased the abortion rates of both minor and nonminor teens.

Neither a Mandatory Counseling Law nor a two-visit law is statistically significant. This suggests that both laws 
represent a negligible increase in the effective total cost to women of obtaining an abortion of an unintended pregnancy. (i.e., no state requires that a woman certify that she actually read or received the written material. In most cases, all that is required is that the woman be given or informed of the availability of the materials.)

\section{Restrictive Abortion Laws and Fetal Losses}

The total number of pregnancies is the sum of births plus abortions plus fetal losses (miscarriages or spontaneous abortions). Virtually all studies on the impact of restrictive abortion laws measure the number of pregnancies as the sum of births and abortions. The main shortcoming of this pregnancy measure is that it implicitly assumes that restrictive abortion laws have no effect on the likelihood of experiencing a pregnancy loss.

Women with unintended pregnancies may be less prepared emotionally and financially for the rigors of childrearing. They may have less concern about how their behavior affects the health of the fetus than women with intended pregnancies [30]. Joyce and Grossman [31] argue that restrictive abortion laws may induce women with unintended pregnancies to smoke or use alcohol or drugs that are harmful to the fetus. A restrictive abortion law may have an effect on fetal losses if women with unintended pregnancies do not provide adequate prenatal care or engage in destructive behaviors resulting in a miscarriage. The relationship between restrictive abortion laws and the prenatal behavior of women with unintended pregnancies has not been systematically analyzed. The Finer and Kost data provides a state-by-state estimate of the number of unintended pregnancies that resulted in fetal losses. This data provides the opportunity to test whether restrictive abortion laws increase the incidence of fetal losses.

The abortion demand equation (3) is reestimated with the dependent variable being either the fetal loss ratio (the number of fetal losses of unintended pregnancies per 1000 unintended pregnancies) or the fetal loss rate (the number of fetal losses of unintended pregnancies per 1000 women of reproductive age). The estimated coefficients for the abortion cost variables (the complete empirical results are available upon request) appear in Table 3, column 1, for the fetal loss ratio and column 2 for the fetal loss rate.

The empirical results for the fetal loss ratio in column 1 find that the abortion price $(P<.05)$, two-visit law $(P<.01)$, and a parental involvement law $(P<.01)$ are significantly positive, which suggests that, for women with unintended pregnancies, fetal losses are related to these abortion cost variables. This result is consistent with the interpretation that the effect of these abortion restrictions is to induce women with unintended pregnancies and who would otherwise have an abortion, to engage in destructive behaviors that are detrimental to the fetus and cause fetal losses.

Both the abortion price $(P<.05)$ and no Medicaid funding $(P<.01)$ are significantly negative for the fetal loss rate in column 2 . This suggests that increases in the abortion price and a Medicaid funding restriction reduce the
TABLE 3: Regression coefficients of abortion cost variables on fetal losses.

\begin{tabular}{lcc}
\hline \multirow{2}{*}{ Abortion cost variables } & \multicolumn{2}{c}{ Dependent variable } \\
& Fetal loss ratio (1) & Fetal loss rate (2) \\
\hline Abortion price & $.1125(2.01)^{* *}$ & $-.0102(2.11)^{* *}$ \\
No Medicaid funding & $2.4665(.45)$ & $-1.1462(2.23)^{* *}$ \\
Parental involvement law & $15.0929(3.19)^{* * *}$ & $-.6471(1.55)$ \\
Mandatory counseling law & $-1.0463(.24)$ & $.1308(.31)$ \\
Two-visit law & $17.4248(3.11)^{* * *}$ & $.5056(1.55)$ \\
\hline$R^{2}$ & .81 & .67 \\
\hline
\end{tabular}

Absolute value of $t$-statistics in parentheses; ${ }^{*} P<.10,{ }^{* *} P<.05,{ }^{* * *} P<$ .01 . Fetal loss ratio is the number of fetal losses of unintended pregnancies per 1000 unintended pregnancies. Fetal loss rate is the number of fetal losses of unintended pregnancies per 1000 women of childbearing ages 15-44 years.

kind of risky noncontracepted sexual activity that leads to unintended pregnancies and, concomitantly, fetal losses from those unintended pregnancies.

\section{Conclusion}

The Supreme Court's 1973 Roe v. Wade decision legalizing abortion recognized that states have a right to regulate abortion access. The 1992 Planned Parenthood of Southeastern Pennsylvania $v$. Casey reaffirmed that right as long as the state law or regulation did not impose an "undue burden" on women seeking an abortion of a nonviable fetus. Restrictive state abortion laws make it more difficult and expensive for women to obtain an abortion. Laws that restrict the access or availability of abortion increase the cost of terminating unintended pregnancies. Making abortions more costly should reduce the number of abortions of unintended pregnancies. A primary focus of the literature has been determining the relationship between the demand for abortion and various restrictive state abortion laws. Because of data limitations, these studies typically examine abortions as a share of pregnancies (unintended plus intended).

However, abortion is a function of unintended pregnancy, and the theoretically correct variable is the incidence of unintended pregnancies that result in an abortion. The problem is that data on unintended pregnancies was unavailable. Finer and Kost [1], using the Centers for Disease Control's Pregnancy Risk Assessment Monitoring System's 2006 state survey of women's pregnancy intentions before, during and after a birth, calculated the number of unintended pregnancies and the number of abortions of unintended pregnancies in all 50 states. This data makes it possible to estimate the impact of restrictive state abortion laws on the incidence of unintended pregnancies that result in an abortion in 2006.

The empirical results find statistically significant negative relationships between particular restrictive state abortion laws and the abortion rate of unintended pregnancies (the number of abortions of unintended pregnancies per 1000 women of childbearing age) and the abortion ratio of unintended pregnancies (the number of abortions of 
unintended pregnancies per 1000 unintended pregnancies). Specifically, a higher abortion price is associated with significant decreases in both the abortion rate and the abortion ratio of unintended pregnancies. In addition, the abortion ratio and the abortion rate of unintended pregnancies are more sensitive to increases in the abortion price than previous estimates that analyzed total pregnancies (unintended and intended).

A Medicaid funding restriction has very little effect on a state's abortion rate, but causes a larger decrease (12 percentage points) in the number of abortions of unintended pregnancies of the low-income population than the previous numerical estimates of 3 to 5 percent using total pregnancies. A parental involvement law is associated with a significant reduction in a state's abortion rate and abortion ratio of unintended pregnancies. Since parental involvement laws affect only unmarried teen minors, this result is consistent with the hypothesis that parental involvement laws have temporal effects that induce a permanent change in the unprotected sexual behavior of teen minors which is perpetuated as they age producing fewer unintended pregnancies and, concomitantly, fewer abortions of unintended pregnancies.

Neither a mandatory counseling law nor a two-visit law has a significant effect on a state's abortion rate or abortion ratio of unintended pregnancies. This suggests that both restrictive abortion laws represent a negligible increase in the effective total cost to women of obtaining an abortion of an unintended pregnancy.

Finally, a higher abortion price and a Medicaid funding restriction are associated with significant decreases in a state's fetal loss rate of unintended pregnancies (the number of fetal losses of unintended pregnancies per 1000 women of reproductive age). This result suggests that these two abortion cost variables reduce the number of unintended pregnancies and correspondingly the fetal losses from those unintended pregnancies. For women with unintended pregnancies (the fetal loss ratio), the abortion price, two-visit laws, and parental involvement laws are associated with increases in fetal losses. Women with unintended pregnancies, and who would otherwise have an abortion, engage in behaviors detrimental to their fetuses causing an increase in fetal losses.

\section{References}

[1] L. B. Finer and K. Kost, "Unintended pregnancy rates at the state level," Perspectives on Sexual and Reproductive Health, vol. 43, no. 2, pp. 78-87, 2011.

[2] M. Bitler and M. Zavodny, "The effect of abortion restrictions on the timing of abortions," Journal of Health Economics, vol. 20, no. 6, pp. 1011-1032, 2001.

[3] R. M. Blank, C. C. George, and R. A. London, "State abortion rates. The impact of policies, providers, politics, demographics, and economic environment," Journal of Health Economics, vol. 15, no. 5, pp. 513-553, 1996.

[4] D. Haas-Wilson, "Women's reproductive choices: the impact of medicaid funding restrictions," Family Planning Perspectives, vol. 29, no. 5, pp. 228-233, 1997.

[5] P. B. Levine, A. B. Trainor, and D. J. Zimmerman, "The effect of Medicaid abortion funding restrictions on abortions, pregnancies and births," Journal of Health Economics, vol. 15, no. 5, pp. 555-578, 1996.

[6] M. H. Medoff, "Price, restrictions and abortion demand," Journal of Family and Economic Issues, vol. 28, no. 4, pp. 583599, 2007.

[7] S. Matthews, D. Ribar, and M. Wilhelm, "The effects of economic conditions and access to reproductive health services on state abortion rates and birthrates," Family Planning Perspectives, vol. 29, no. 2, pp. 52-60, 1997.

[8] M. H. Medoff, "State abortion policies, targeted regulation of abortion provider laws, and abortion demand," Review of Policy Research, vol. 27, no. 5, pp. 577-594, 2010.

[9] M. H. Medoff, "State abortion policy and the long-term impact of parental involvement laws," Politics and Policy, vol. 38, no. 2, pp. 193-221, 2010.

[10] M. H. Medoff, "The response of abortion demand to changes in abortion costs," Social Indicators Research, vol. 87, no. 2, pp. 329-346, 2008.

[11] U.S. Bureau of the Census and U.S. Census of the Population, State Reports, 2000, U. S. Government Printing Office, Washington, DC, USA, 2003.

[12] Association of Religious Data Archives, U. S. Membership Report: Religious Traditions, http://www.thearda.com.

[13] Guttmacher Institute, State Policies in Brief, Alan Guttmacher Institute, New York, NY, USA, 2006.

[14] G. S. Becker, "An economic analysis of fertility," in Demographic and Economic Change in Developed Countries, C. Christ, Ed., pp. 209-231, Princeton University Press, Princeton, NJ, USA, 1960.

[15] R. T. Michael, "Education and the derived demand for children," Journal of Political Economy, vol. 81, no. 2, pp. 128164, 1973.

[16] R. J. Willis, "A new approach to the economic theory of fertility behavior," Journal of Political Economy, vol. 81, no. 2, pp. 1464, 1973.

[17] M. P. Gius, "The impact of provider availability and legal restrictions on the demand for abortions by young women," Social Science Journal, vol. 44, no. 3, pp. 495-506, 2007.

[18] R. T. Jewell and R. W. Brown, "An economic analysis of abortion: the effect of travel cost on teenagers," Social Science Journal, vol. 37, no. 1, pp. 113-124, 2000.

[19] M. H. Medoff, "A pooled time-series analysis of abortion demand," Population Research and Policy Review, vol. 16, no. 6, pp. 597-605, 1997.

[20] NARAL Foundation, Who Decides? The Status of Women's Reproductive Rights in the United States, NARAL Foundation, Washington, DC, USA, 2006.

[21] P. B. Levine, Sex and Consequences: Abortion Policy and the Economics of Fertility, Princeton University Press, Princeton, NJ, USA, 2004.

[22] W. H. Greene, Econometric Analysis, Prentice Hall, Upper Saddle River, NJ, USA, 2007.

[23] D. N. McCloskey and S. Ziliak, "The standard error of regressions," Journal of Economic Literature, vol. 34, no. 1, pp. 97-114, 1996.

[24] D. Gujarati, Basic Econometrics, McGraw-Hill, New York, NY, USA, 1995.

[25] C. Garbacz, "Abortion demand," Population Research \& Policy Review, vol. 9, no. 2, pp. 151-160, 1990.

[26] S. F. Gohmann and R. L. Ohsfeldt, "Effects of price and availability on abortion demand," Contemporary Policy Issues, vol. 11, no. 4, pp. 42-55, 1993. 
[27] T. J. Kane and D. Staiger, "Teen motherhood and abortion access," Quarterly Journal of Economics, vol. 111, no. 2, pp. 467-506, 1996.

[28] T. Joyce and R. Kaestner, "The impact of mandatory waiting periods and parental consent laws on the timing of abortion and state of occurrence among adolescents in Mississippi and South Carolina," Journal of Policy Analysis and Management, vol. 20, no. 2, pp. 263-282, 2001.

[29] A. Tomal, "Parental involvement laws and minor and nonminor teen abortion and birth rates," Journal of Family and Economic Issues, vol. 20, no. 2, pp. 149-162, 1999.

[30] W. Marsiglio and F. L. Mott, "Does wanting to become pregnant with a first child affect subsequent maternal behaviors and infant birth weight?" Journal of Marriage and Family, vol. 50, no. 4, pp. 1023-1036, 1988.

[31] T. J. Joyce and M. Grossman, "Pregnancy wantedness and the early initiation of prenatal care," Demography, vol. 27, no. 1, pp. 1-17, 1990. 


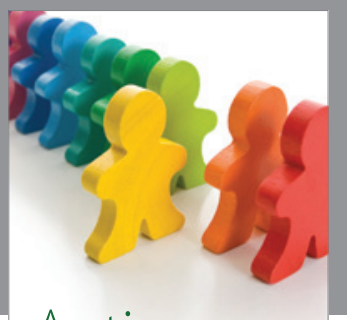

Autism

Research and Treatment
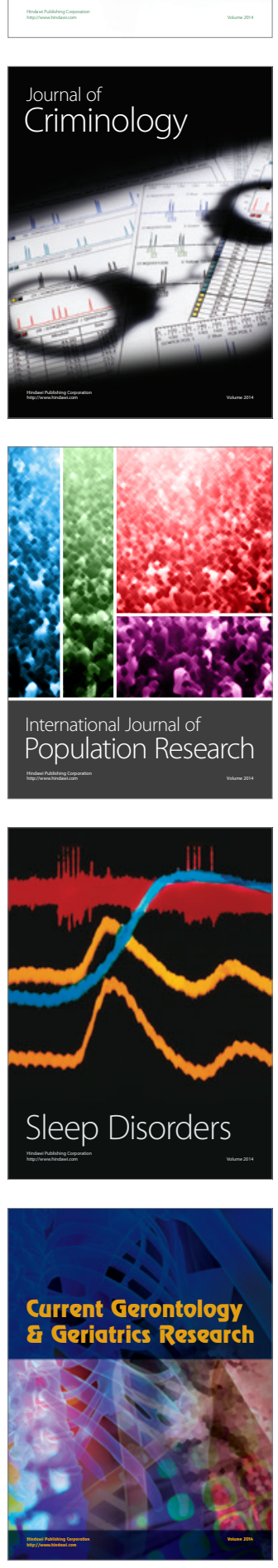
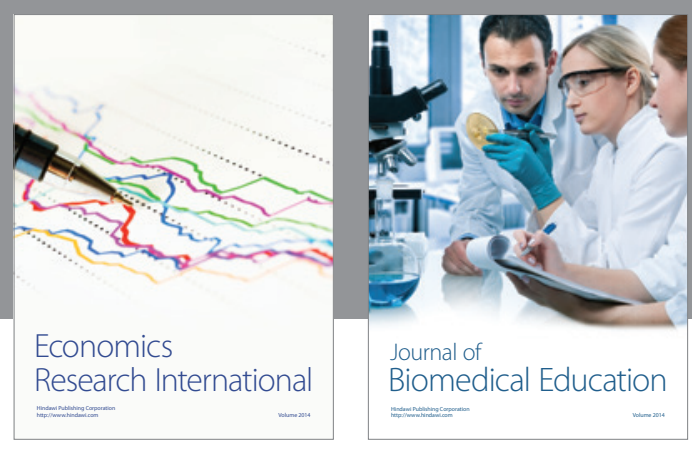

Journal of

Biomedical Education

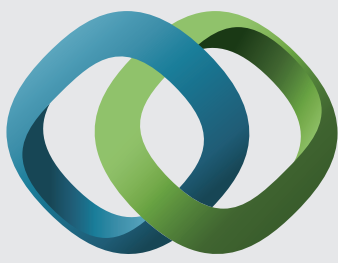

\section{Hindawi}

Submit your manuscripts at

http://www.hindawi.com
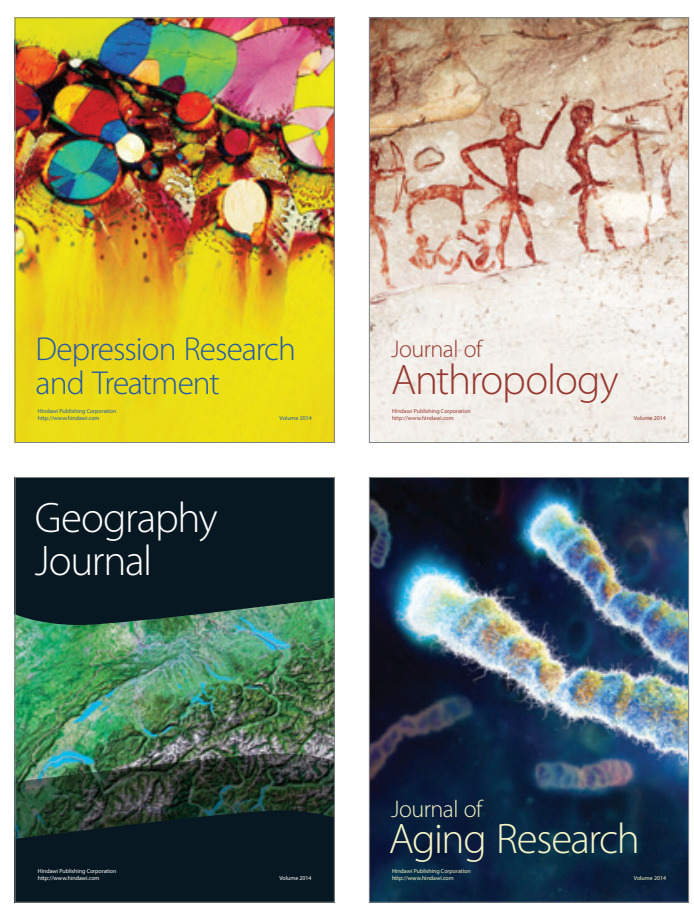

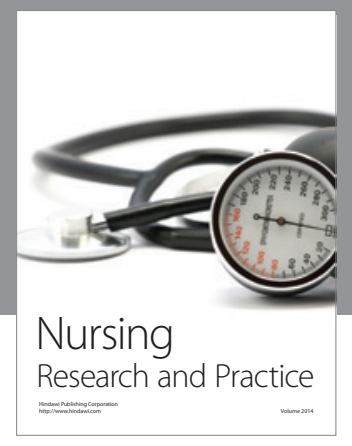

Nursing

Research and Practice

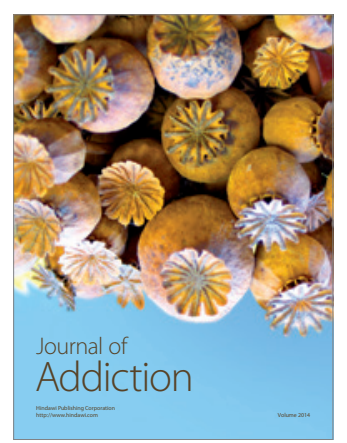

Child Development

Research

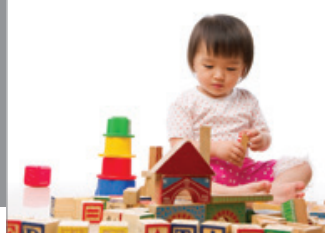

迥
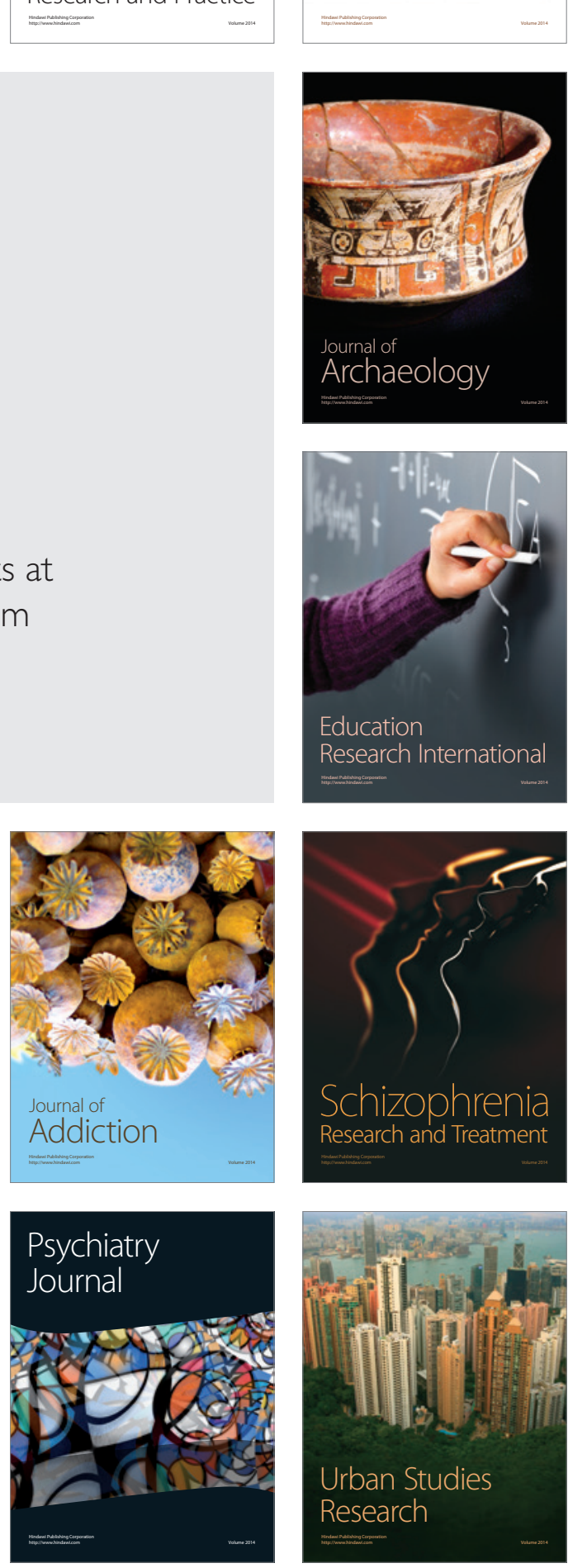